\title{
Comparative study of the side effect profiles of oral misoprostol and parenteral oxytocin used in prevention of postpartum haemorrhage in Maiduguri Nigeria*
}

\author{
Sadiq G. Uthman ${ }^{1 \#}$, Mairiga A. Garba ${ }^{2}$, Ado G. Danazumi ${ }^{2}$, Mairo U. Mandara ${ }^{3}$, \\ Nwaosu H. Sylvester ${ }^{4}$ \\ ${ }^{1}$ Department of Ethno-Pharmacy and Drug Development, Faculty of Pharmacy, University of Maiduguri, Maiduguri, Nigeria \\ ${ }^{2}$ Department of Obstetrics and Gynaecology, University of Maiduguri, Maiduguri, Nigeria \\ ${ }^{3}$ Population and Reproductive Health Research Initiative of Department of Obstetrics and Gynaecology, Ahmadu Bello University \\ Teaching Hopspital, Zaria, Nigeria \\ ${ }^{4}$ Department of Maths and Statistics, Faculty of Science, University of Maiduguri, Maiduguri, Nigeria \\ Email: "garbaus2000@yahoo.co.uk
}

Received 29 September 2012; revised 30 October 2012; accepted 8 November 2012

\begin{abstract}
The following work compared adverse effects profile and patients' acceptability of intra-venous oxytocin 10 iu and oral misoprostol 600 ug used in the prevention of postpartum hemorrhage in the third stage of labour. A total of 1865 pregnant women who have received either oxytocin injection or oral misoprostol in third stage of labour as prophylaxis for postpartum haemorrhage, were enrolled within three health care facilities in Maiduguri, Nigeria. Each patient was observed at parturition and for $\mathbf{2 4} \mathrm{h}$ after during which oral interviews were conducted and clinical notes studied. The oxytocin medication group exhibited higher abdominal pains $(7.1 \%$ versus $0.0 \% ; p<0.001)$ and headache $(1.9 \%$ versus $0.1 \% ; p<0.001)$, while the misoprostol group showed higher shivering (33.9\% versus $0.0 \% ; p<0.001)$ and fever $(19.7 \%$ versus $1.8 \% ; \mathrm{p}<0.001)$. There were no significant differences in other side effects like nausea and vomiting. There was no statistically significant $(p>0.05)$ difference in patients acceptability of injectable oxytocin (99.3\%) and oral misoprostol (98.3\%). Oxytocin usage in the prevention of PPH was associated with abdominal pains and headache while misoprostol was associated with shivering and fever. Patients from this study have demonstrated high level of acceptability of both parenteral oxytocin and oral misopristol prevention of post-partum haemorrhage.
\end{abstract}

Keywords: Adverse Effects; Treatment Acceptability; Postpartum Haemorrhage; Misoprostol; Oxytocin

*Conflict of interest: The authors do not have any conflict of interest.

\#Corresponding author.

\section{INTRODUCTION}

The leading cause of Postpartum Haemorrhage (PPH) is uterine atony, which is generally preventable by the use of uterotonics, among which oxytocin is preferred in hospital-based settings [1-3]. However, use of oxytocin has a lot of limitations in low-income countries where births still occur at home with untrained birth attendants who do not practice active management of the third stage of labour (AMTSL) [2,4-7]. Other uterotonic agents such as oral misoprostol have been shown to be effective for the prevention of PPH but its use have been limited by incidences of adverse effects like shivering and vomiting, and as such it is yet to be implemented as standard care in low-resource settings $[8,9]$. There were reports of more adverse effects associated with the use of misoprostol in prevention of PPH than use of parenteral oxytocin [10]. Furthermore, these adverse effects of misoprostol were found to be more with sublingual administration than in rectal [10]. The idea of defining a more suitable (perhaps more patient friendly) misoprostol route, and comparing its adverse effects with that of the conventional parenteral oxytocin, is a crucial therapeutic issue.

The purpose of this study is to compare adverse effects and acceptability of intra-venous oxytocin $10 \mathrm{iu}$ and oral misoprostol tablet 600 ug use in the prevention of PPH in the third stage of labour.

\section{MATERIALS AND METHODS}

The study was a prospective, comparative and multicentred, started in September 2007 and completed in March 2009. It was conducted in three health institutions in Maiduguri metropolitan area of Borno state, Nigeria. These were; the University of Maiduguri Teaching Hos- 
pital (UMTH), the Maiduguri Specialist Hospital, and Yerwa Maternal and Child Health Care Centre. Women that had uncomplicated vaginal delivery and were administered with either oxytocin injection or misoprostol tablet as per ethics of institutional practice, were recruited for the study. The study was completed with a total sample size of 1865 orally consenting (some written) enrolees. However, 46 of the administered questionnaire were invalidated for various reasons leaving a total of 1819 valid questionnaires (912 for oxytocin and 907 for misoprostol). The data was further reduced to 1800 through a process of computer randomization so as to have equal study population in the two medication groups (900 women for each oxytocin and misoprostol groups).

The women that fall in oxytocin group received 10 iu of oxytocin intravenously (Labtocin; LABORATE Pharm India) at delivery of the anterior shoulder. In the oral misoprostol group, $600 \mu \mathrm{g}(3 \times 200 \mu \mathrm{g})$ misoprostol tablets (Cytotec; Emzor Pharm Limited, Isolo, Lagos) were administered within three minutes of the delivery of baby if there is no any nausea and vomiting. In all patients the uterus was always gently massaged to ensure contraction. The exclusion criteria included Known allergy to either of the drugs, operative delivery, history of co-morbid conditions like diabetes, mal-presentation, anaemia, antepartum haemorrhage, multiple pregnancy, and grand-multiparity (greater than six births).

Ethical approvals were obtained from the research and ethical committees of the UMTH and that of Maiduguri Specialist Hospital. Ethical approval from Yerwa Maternal and Child Health Care Centre was obtained from the Local Administrators. All procedures were conducted according to the participating institutions' ethical guidelines and good clinical practice was adhered to. The minimum sample size for the study was calculated using the Taylors' formula at $95 \%$ confidence taking prevalence of PPH to be $50 \%$. This gave a minimal required sample size of 385. However, over 1800 patients were enrolled for the study in order to take care of attrition and to increase power. The statistical software SPSS version 16 (SPSS Chi, Ill USA) was used for statistical analysis. Chi square statistical $\left(\chi^{2}\right)$ test was used to compare the occurrences of observed adverse effects between the two medication groups. The level of significance was set at $p$ $<0.05$ and $\mathrm{p}<0.001$.

\section{RESULTS}

Table 1 shows the side effect profile of the two medication groups, the oxytocin medication group exhibited higher abdominal pains $(7.1 \%$ versus $0.0 \%$; $<0.001)$ and headache $(1.9 \%$ versus $0.1 \% ; \mathrm{p}<0.001)$. On the other hand, the misoprostol medication group showed higher shivering $(33.9 \%$ versus $0.0 \% ; \mathrm{p}<0.001)$ and fever $(19.7 \%$ versus $1.8 \% ; p<0.001)$. There were no significant differences in other side effects like nausea and vomiting. There was no excessive blood loss $(>1000$ $\mathrm{ml}$ ) in any of the two medication groups. There was no significant difference in patients' oral reporting of satisfaction and acceptability of parenteral oxytocin and oral misopristol in the prevention of PPH (Table 2).

\section{DISCUSSIONS}

Shivering was identified as the most common adverse

Table 1. The frequency of some adverse effects in the two medication groups of intravenous oxytocin (900 subjects) and oral misoprostol tablet ( 900 subjects).

\begin{tabular}{|c|c|c|c|c|c|}
\hline \multirow{2}{*}{ Adverse Effects } & \multirow{2}{*}{ Medication Group } & \multicolumn{3}{|c|}{ Occurrence of the Adverse Effects Number (\%) } & \multirow{2}{*}{ P-value } \\
\hline & & No & Yes & Total & \\
\hline \multirow{2}{*}{ Nausea } & Oxytocin & $883(98.1)$ & $17(1.9)$ & $900(100)$ & \multirow{2}{*}{$>0.05$} \\
\hline & Misoprostol & $884(98.2)$ & $16(1.8)$ & $900(100)$ & \\
\hline \multirow{2}{*}{ Vomiting } & Oxytocin & $867(96.3)$ & $33(3.7)$ & $900(100)$ & \multirow{2}{*}{$>0.05$} \\
\hline & Misoprostol & $867(96.3)$ & $33(3.7)$ & $900(100)$ & \\
\hline \multirow{2}{*}{ Abdominal Pains } & Oxytocin & $836(92.9)$ & $64(7.1)$ & $900(100)$ & \multirow{2}{*}{$<0.001$} \\
\hline & Misoprostol & $900(100)$ & $0(0.0)$ & $900(100)$ & \\
\hline \multirow{2}{*}{ Shivering } & Oxytocin & $900(100)$ & $0(0.0)$ & $900(100)$ & \multirow{2}{*}{$<0.001$} \\
\hline & Misoprostol & $595(66.1)$ & $305(33.9)$ & $900(100)$ & \\
\hline \multirow{2}{*}{ Fever } & Oxytocin & 884 (98.2) & $16(1.8)$ & $900(100)$ & \multirow{2}{*}{$<0.001$} \\
\hline & Misoprostol & $723(80.3)$ & $177(19.7)$ & $900(100)$ & \\
\hline \multirow{2}{*}{ Headache } & Oxytocin & $883(98.1)$ & $17(1.9)$ & $900(100)$ & \multirow{2}{*}{$<0.001$} \\
\hline & Misoprostol & 899 (99.9) & $1(0.1)$ & $900(100)$ & \\
\hline
\end{tabular}

${ }^{*}$ Chi-square statistics; Enrollees in the oxytocin medication groups exhibited higher preponderance of abdominal pains and headache while those in misoprostol group exhibited higher fever and shivering. 
Table 2. Patients aacceptability of management approach in the two medication groups of intravenous oxytocin and oral misoprostol tablet.

\begin{tabular}{cccc}
\hline \multirow{2}{*}{$\begin{array}{c}\text { Medication } \\
\text { Group }\end{array}$} & \multicolumn{2}{c}{$\begin{array}{c}\text { Acceptability of Patients } \\
\text { Number (\%) }\end{array}$} & \multirow{2}{*}{ Total } \\
\cline { 2 - 3 } & No & Yes & \\
\hline i.v. Oxytocin & $6(0.7)$ & $799(99.3)$ & $805(100)$ \\
p.o. Misoprostol & $14(1.7)$ & $792(98.3)$ & $806(100)$ \\
Total & 20 & 1591 & 1611 \\
\hline
\end{tabular}

$\mathrm{p}>0.05$ for the difference in acceptability of medication strategy by chi square statistics.

effect of misoprostol. This agreed with the work of Hofmeyr et al. (1998) and Amant et al. (1999) which reported preponderances of $19 \%$ and $42 \%$ respectively $[11,12]$.

In a randomised controlled comparison between orally administered misoprostol and standard management in Universitty College Hospital, London, El-Refaey et al., (2000) concluded that many side effects were less common with misoprostol but shivering and pyrexia were more common. In 2006, the WHO held a Technical Consultation on the Prevention of PPH and reported that oral misoprostol was associated with more shivering and temperature $>38^{\circ} \mathrm{C}[13,14]$.

In two separate studies; a randomized placebo-controlled misoprostol trial (Surbek et al., 1999) and a double-blind randomized trial comparing misoprostol with methylergometrine for the prevention of postpartum hemorrhage (Amant et al., 1999), higher preponderance of shivering was reported in the misoprostol group. Furthermore, there were no differences between the groups in the two studies in terms of Nausea and Vomiting, thus agreeing with the present research work $[12,15]$.

Walley et al. (2000), reported same statistically significant preponderance of shivering in misoprostol group than in oxytocin group ( $22.2 \%$ versus $5.7 \%$ ), and no difference in the two groups in terms of nausea, vomiting, and diarrhoea [16]. $\mathrm{Ng}$ et al. (2001) also reported that shivering was significantly higher in the misoprostol group (30.2\% in the misoprostol group vs $9.9 \%$ in ergometrine group) [3].

In disagreement with the present outcome, some research work had indicated cases of diarrhoea $(3 \%)$ in misoprostol group $[13,17,18]$. In another twist, El-Refaey et al. (2000) reported significantly higher incidences of nausea in misoprostol medication group than in standard oxytocics.

The use of other routes of administeration was shown to be associated with varying degree of side effects. The rectal route for example, was shown to be associated with milder side effects than the oral routes $[19,20]$. On the other hand rectal rout tends to exhibit higher cases of side effects. Zieman et al. (1997) reported increased risks of shivering with sublingual misoprostol tablets [21].

It is significant to note that there was no statistically significant difference in the acceptability of treatment approach in the two medication groups (Table 2). According to Chama (2009), clinicians abhor the idea of per os administration of misoprostol post-partum (for prevention of PPH) because it will add up to the stress of birth. The idea behind running this test was that the intravenous administration of oxytocin was done without the subjects' slightest effort. On the other hand, the oral misoprostol needs a lot of subject's participation, thus culminating in the acclaimed stress. However, there was no statistically significant difference between the patients' acceptability of the two therapeutic approaches in this study

\section{CONCLUSIONS}

The use of both parenteral Oxytocin and oral Misopristol have demonstrated high level of safety in that there were no serious adverse effects. However, there was preponderance of abdominal pains and headache in the oxytocin group while misoprostol exhibited higher fever and shivering. The proportion of patients that exhibited shivering and fever was high enough to raise concern in the misoprostol medication group. There was also no significant difference in the frequency of nausea and vomiting between the two populations. Though Diarrhoea was reported as an adverse effect of oral misoprostol $[14,17,18]$, it was not observed in this study.

There was no difference in terms of acceptability of medication strategy within the two study populations. The art of patient counselling in misoprostol medication should be designed such as shivering, as a major adverse effect, is adequately enshrined in the counselling plan.

\section{ACKNOWLEDGEMENTS}

We are very grateful to Professor Ibrahim Abdu-Aguye, Professor Isah M. Hussaini, Professor Karnius S. Gamaniel for co-supervising this work. We are also grateful to the University of Maiduguri, Nigeria, for funding this work (in part) and to Emzor Pharmaceutical Industries Limited Nigeria, for donating misoprostol tablets. We are very grateful to members of the research and ethical committee of the participating health institutions; especially Mal. Babale Usman of the University of Maiduguri Teaching Hospital, and Dr Guludze of Borno State Specialist Hospital-for giving us not only the permission but their immense advice and suggestions. We are also grateful to the entire staff of the labor wards in the three study sites; more so the matrons in-charge of the wards; who ensured that the project went on smoothly. All the consultant obstetricians and medical officers of the department of Obstetrics and Gynecology, University of Maiduguri Teaching Hospital and those of State Specialist Hospital also contributed in no small measure in the success of the project through their suggestions and criticisms. 
The contributions of Dr Abdul, Prof. Shittu and Dr (Mrs) Madugu of the department of Obstetrics and Gynecology ABUTH Zaria is appreciated. Finally, we humbly give thanks and appreciations to our colleagues at the following three institutions; UMTH Pharmacy department, the Faculty of Pharmacy, University of Maiduguri, and those at the Faculty of Pharmacy ABU Zaria.

\section{REFERENCES}

[1] Gulmezoglu, A.M., Villar, J., Ngoc, N.T., et al. (2001) Trial of misoprostol in the management of the third stage of labour. Lancet, 358, 689-695. doi:10.1016/S0140-6736(01)05835-4

[2] Langenbach, C. (2006) Misoprostol in preventing postpartum hemorrhage: A meta-analysis. International Journal of Gynecology \& Obstetrics, 92, 10-18.

[3] Ng, P.S., Chan, A.S., Sin, W.K., et al. (2001) A multicentre randomized controlled trial of oral misoprostol and im syntometrine in the management of the third stage of labour. Human Reproduction, 16, 31-35. doi:10.1093/humrep/16.1.31

[4] Selo-Ojeme, D.O. (2002) Primary postpartum haemorrhage. Journal of Obstetrics and Gynecology, 22, 463469. doi:10.1080/0144361021000003555

[5] Kodkany, B.S., Derman, R.J., Goudar, S.S., et al. (2004) Initiating a novel therapy in preventing postpartum hemorrhage in rural India: A joint collaboration between the United States and India. International Journal of Fertility and Women's Medicine, 49, 91-96.

[6] Miller, S., Lester, F. and Hensleigh, P. (2004) Prevention and treatment of postpartum hemorrhage: New advances for low-resource settings. Journal of Midwifery \& Women's Health, 49, 283-292. doi:10.1016/j.jmwh.2004.04.001

[7] Walraven, G., Blum, J., Dampha, Y., et al. (2005) Misoprostol in the management of the third stage of labour in the home delivery setting in rural Gambia: A randomized controlled trial. International Journal of Obstetrics \& Gynaecology, 112, 1277-1283.

[8] Derman, R.J., Kodkany, B.S., Goudar, S.S., et al. (2006) Oral misoprostol in preventing postpartum haemorrhage in resource-poor communities: A randomised controlled trial. Lancet, 368, 1248-1253. doi:10.1016/S0140-6736(06)69522-6

[9] JHPIEGO (2011) Program brief on maternal and neonatal health program preventing postpartum hemorrhage. http://www.jhpiego.org/resources/pubs/mnh/PPHpgmbrie f.pdf

[10] Tang, O.S., Schweer, H., Seyberth, H.W., et al. (2002) Pharmacokinetics of different routes of administration of misoprostol. Human Reproduction, 17, 332-336. doi:10.1093/humrep/17.2.332

[11] Hofmeyer, G.J., Nikodem, V.C. and De Jager, M. (1998) A randomized placebo controlled trial of oral misoprostol in the third stage of labour. British Journal of Obstetrics and Gynaecology, 105, 971-875. doi:10.1111/j.1471-0528.1998.tb10259.x

[12] Amant, F., Spitz, B. and Timmerman, D. (1999) Misoprostol compared with methylergometrine for the prevention of postpartum haemorrhage. British Journal of $\mathrm{Ob}$ stetrics and Gynaecology, 106, 1066-1070. doi:10.1111/j.1471-0528.1999.tb08115.x

[13] El-Refaey, H., Nooh, R. and O'Brien, P. (2000) The misoprostol third stage of labour study. British Journal of Obstetrics and Gynaecology, 107, 1104-1110. doi:10.1111/j.1471-0528.2000.tb11108.x

[14] WHO (2006) WHO Guidelines for the prevention of postpartum haemorrhage. www.who.int/making.../WHORecommendationsforPPHa emorrhage.pdf

[15] Surbek, D.V., Fehr, P.M. and Hosli, I. (1999) Oral misoprostol for third stage of labor; a randomized placebocontrolled trial. Obstetrics and Gynaecology, 94, 255-258. doi:10.1016/S0029-7844(99)00271-9

[16] Walley, R.L., Wilson, J.B. and Crane, J.M.G. (2000) A double-blind placebo controlled randomised trial of misoprostol and oxytocin in the management of the third stage of labour. British Journal of Obstetrics and Gynaecology, 107, 1111-1115. doi:10.1111/j.1471-0528.2000.tb11109.x

[17] El-Refaey, H., O’Brien, P. and Morafa, W. (1996) Misoprostol for the third stage of labor. Lancet, 347, 1257. doi:10.1016/S0140-6736(96)90771-0

[18] El-Refaey, H., O’Brien, P. and Morafa, W. (1997) Use of misoprostol in the prevention of postpartum hemorrhage. British Journal of Obstetrics and Gynaecology, 104, 336339. doi:10.1111/j.1471-0528.1997.tb11464.x

[19] Bamigboye, A.A., Merrell, D.A. and Hofmeyer, G.J. (1998) Randomized comparison of rectal misoprostol with syntometrine for the management of the third stage of labor. Acta Obstetricia et Gynecologica Scandinavica, 77, 178-181. doi:10.1080/j.1600-0412.1998.770209.x

[20] Diab, K.M., Ramy, A.R. and Yehia, M.A. (1999) The use of rectal misoprostol in 140 subjects as active pharmacological management of the third stage of labor. Journal of Obstetrics and Gynaecology Research, 25, 327-332. doi:10.1111/j.1447-0756.1999.tb01171.x

[21] Zieman, M., Fong, S.K. and Benonitz, N.L. (1997) Kinetics of misoprostol with oral or vaginal administration. Obstetrics \& Gynecology, 90, 88-92. doi:10.1016/S0029-7844(97)00111-7 